\title{
ARTICLE
}

\section{Comparison of airborne and ground-based tools used for radiation measurement in the environment}

\author{
Kotaro Ochi ${ }^{a^{*}}$, Miyuki Sasaki ${ }^{\mathrm{a}}$, Mutsushi Ishida ${ }^{\mathrm{b}}$ and Yukihisa Sanada ${ }^{\mathrm{a}}$ \\ ${ }^{a}$ Fukushima Environmental Safety Center, Japan Atomic Energy Agency, 45-169 Sukakeba, Kaibama-aza, Haramachi, Minamisoma, \\ Fukushima, 975-0036, Japan; ${ }^{b}$ NESI Inc., 38 Shinko-cho, Hitachinaka, Ibaraki, 312-0005, Japan
}

\begin{abstract}
After the Fukushima Daiichi nuclear power plant accident, some airborne and ground radiation measurement techniques have been applied to the environmental radiation measurements. These methods have been used in different situations depending on the spatial distribution of air dose rate in the environment. In our previous studies, the most effective tool was selected in response to the feature of targeted environment. However, airborne and ground radiation measurement results have not yet been evaluated and compared in the same environment. In this study, we attempted to quantitatively evaluate the results of airborne and ground radiation measurements with the parameter of normalized mean square error in the same farm. Consequently, the reliability of each measurement technique was quantified. The comparison of different techniques, which is important to effectively monitor the spatial distribution of air dose rate in the environment, could be achieved using this method.
\end{abstract}

Keywords: Fukushima Daiichi Nuclear Power Plant accident; airborne radiation measurement; ground radiation measurement; air dose rate; normalized mean square error

\section{Introduction}

Enormous amounts of radionuclides were released into the environment as a result of the Fukushima Daiichi nuclear power plant (FDNPP) accident. The released FDNPP-derived radionuclides were deposited on the ground surface in East Japan [1]. In previous studies, we performed airborne radiation measurement (ARM) using a manned helicopter for investigating the deposition of radionuclides over a wide area $[2,3]$. ARM using an unmanned helicopter was employed to investigate the local distribution of radionuclides around FDNPP $[4,5]$. In recent years, an unmanned vehicle was used for investigating the air dose rate in parts of the area where people could not enter on foot, such as forests and mountains.

Ground radiation measurement (GRM) tools were developed for investigating the detailed distribution of air dose rate above the ground. Because of its flexible form, a plastic scintillation fiber (PSF) using a truck was suitable to investigate the intensity of radionuclides in response to the features in the targeted area [6]. In our previous studies, GRM using a PSF was performed in water environments such as irrigation ponds and rivers [7]. GRM using a car was useful for rapid and wide investigation of spatial distribution of air dose rate regardless of the undulation above the ground. Tanigaki

*Corresponding author. Email: ochi.kotaro@jaea.go.jp et al. (2013) reported that GRM using a car mounting a radiometric survey system called KURAMA [8].

The ARM and GRM tools were selected to investigate the deposition of radionuclides and air dose rate in response to the features of targeted environment, respectively. However, the comparison between ARM and GRM results has not yet been evaluated in the same environment. To evaluate the effective selection of these tools, we used the parameter called normalized mean square error (NMSE) to quantitatively evaluate the difference in results for each tool based on the result using a handheld survey meter.

\section{Materials and methods}

\subsection{Study site}

We selected an extended farm for study site. Details of the study site $(600 \mathrm{~m} \times 180 \mathrm{~m})$ are shown in Figure 1 . This site is located in the central part of Nishigo-village in Fukushima Prefecture, which is approximately 100 $\mathrm{km}$ southwest of FDNPP. This farm belongs to National Livestock Breeding Center in Japan. Four representative areas (Areas A-D) were selected based on their distinct ranges of the air dose rate above the ground. First, at the study site, the air dose rate at $10 \mathrm{~cm}$ above the ground level (agl.) was measured via a handheld survey meter that uses a CsI scintillator (NSEI Co., Ltd. Ibaraki, Japan). In Figure 1, the air dose rate map based on data 
from the handheld survey meter was superimposed on the photogrammetric map [9]. In this study, measurement results from the radiation measurement tool at our study site were standardized with the handheld survey meter data for quantitative evaluation of the difference between results using each tool.

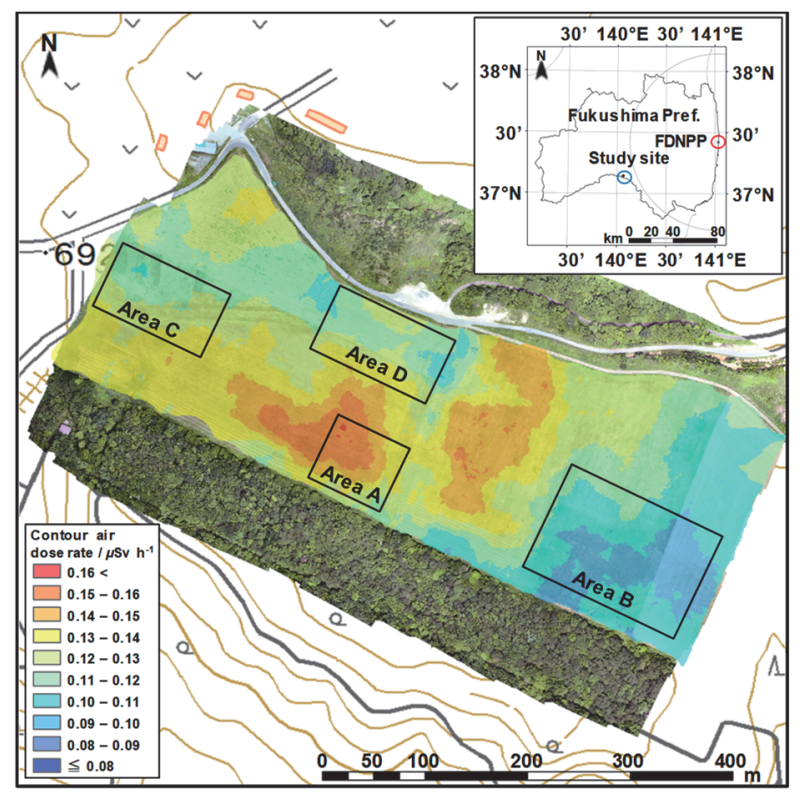

Figure 1. Location of the study site and distribution of air dose rate at $10 \mathrm{~cm}$ agl. [9].

\subsection{Measurement conditions}

\subsubsection{ARM using an unmanned helicopter}

The detailed specifications of each measurement tool and conditions are shown in Table 1. The image of each measurement is shown in Figure 2. The unmanned helicopter, R-MAX G1 (YAMAHA Co., Ltd. Shizuoka, Japan), has previously been employed to spray the pesticides in a paddy field. In our previous studies, we monitored the distribution of air dose rate around FDNPP using the helicopter combined with a radiation detector [4,5]. We mounted a $\mathrm{LaBr}_{3}(\mathrm{Ce})$ detector (Japan Radiation Engineering Co., Ltd. Ibaraki, Japan) and a $\mathrm{CeBr}_{3}$ detector (Japan Radiation Engineering Co., Ltd. Ibaraki, Japan) under the helicopter, respectively. The advantage of the $\mathrm{LaBr}_{3}(\mathrm{Ce})$ detector is able to clearly distinguish the $605 \mathrm{keV}$ peak $\left({ }^{134} \mathrm{Cs}\right)$ from the $662 \mathrm{keV}$ energy peak $\left({ }^{137} \mathrm{Cs}\right)$. In contrast, it was necessary to subtract the gamma-ray count rate derived from ${ }^{138} \mathrm{La}$ and natural nuclides (Ac-series) in the detector from the total gamma-ray count rate. $\mathrm{A} \mathrm{CeBr}_{3}$ detector was minimally influenced by self-contamination compared to $\mathrm{LaBr}_{3}(\mathrm{Ce})$ detector. Using $\mathrm{CeBr}_{3}$ detector is suitable to use for investigating the deposition of natural radionuclide $[4,5]$.

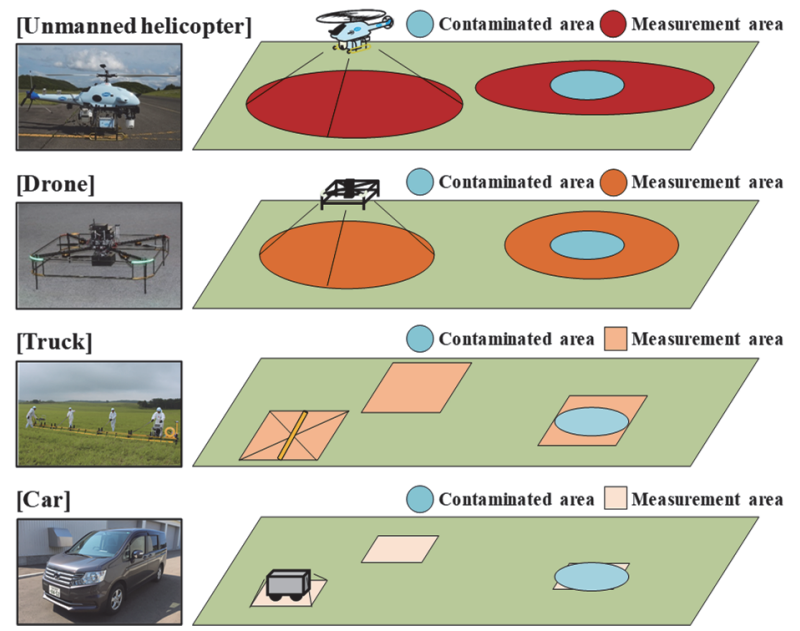

Figure 2. Scale of radiation measurement using each tool.

\subsubsection{ARM using a drone}

The drone (3D robotics Co., Ltd. California, Japan) was widely used to take a photo at bird's eye view. It is possible to continuously fly for $10 \mathrm{~min}$. It is just as easy to switch between manual and programmed flight modes in response to emergency situations as it is with the drone. A gadolinium aluminum gallium garnet scintillation detector (GAGG: Furukawa Co, Ltd, Tokyo, Japan) was mounted under the drone for ARM. We selected the detector in consideration of the payload of the drone.

\subsubsection{GRM using a car}

The car-borne survey tool was useful for rapidly measuring the air dose rate above the ground. Generally, a small detector and a global positioning system (GPS) are combined and installed onto a car [8]. In this study, a car was suitable for mounting the large and heavy device for radiation measurement because air dose rate in the study site was low. Moreover, it is suitable for detailed investigation of the air dose rate above the ground. However, these tools are restricted to use on flat land. We mounted a $\mathrm{NaI}(\mathrm{Tl})$ detector (Radiation Solution Inc. Mississauga, ON, Canada) in the car.

Table 1. Detailed specifications of measurement tool and condition.

\begin{tabular}{|c|c|c|c|c|c|c|c|c|c|c|c|c|}
\hline \multirow{2}{*}{ Device } & \multirow{2}{*}{ Detector } & \multirow{2}{*}{ Measument date } & \multirow{2}{*}{$\begin{array}{c}\text { Fequency of each } \\
\text { measurement } / \mathrm{s}\end{array}$} & \multirow{2}{*}{$\begin{array}{r}\text { Volume of } \\
\text { detector/L }\end{array}$} & \multirow{2}{*}{ GPS } & \multirow{2}{*}{ Height / m } & \multirow{2}{*}{ Speed $/ \mathrm{m} \mathrm{s}^{-1}$} & \multirow{2}{*}{$\begin{array}{c}\text { Distance of each } \\
\text { measurement point } \% * / \mathrm{m}\end{array}$} & \multicolumn{4}{|c|}{ Measurement area } \\
\hline & & & & & & & & & Area A & Area B & Area $\mathrm{C}$ & Area D \\
\hline On Foot & CsI & 6-10 Jun. 2016 & 3 & 0.008 & Single & 0.1 & 1.0 & 3 & 0 & 0 & 0 & 0 \\
\hline \multirow{4}{*}{$\begin{array}{l}\text { Unmanned } \\
\text { helicopter }\end{array}$} & & 6 Jun. 2016 & & & & 10 & 2.0 & 10 & 0 & & & \\
\hline & $\mathrm{LaBr} 3(\mathrm{Ce})$ & 10 Jun. 2016 & 1 & 0.13 & Diffrential & 20 & 4.0 & 20 & 0 & 0 & 0 & 0 \\
\hline & & 9 Jun. 2016 & & & & 30 & 5.0 & 30 & 0 & 0 & 0 & 0 \\
\hline & $\mathrm{CeBr} 3$ & 30 Nov. 2016 & 1 & 0.21 & Diffrential & 10 & 2.0 & 10 & 0 & $\bigcirc$ & 0 & 0 \\
\hline Drone & $\mathrm{Gd}_{3} \mathrm{Al}_{2} \mathrm{Ga}_{3} \mathrm{O}_{12}(\mathrm{Ce})$ & 27-28 Jul. 2016 & 3 & 0.008 & Single & 5 & 2.0 & 10 & $\bigcirc$ & 0 & 0 & \\
\hline Truck & Plastic scintillator & 27-28 Jul. 2016 & 1 & $10 *$ & Diffrential & 0.05 & 1.0 & $0 \% \%$ & 0 & $\mathrm{O}$ & 0 & 0 \\
\hline $\mathrm{Car}$ & $\mathrm{NaI}(\mathrm{Tl})$ & Nov. 28-Dec. 22016 & 1 & 6.3 & Single & 0.5 & 1.0 & 25 & 0 & 0 & 0 & 0 \\
\hline
\end{tabular}




\subsubsection{GRM using a plastic scintillation fiber}

The trucking survey used a PSF (Japan Radiation Engineering Co., Ltd. Ibaraki, Japan) in a vinyl chloride tube, approximately $10 \mathrm{~m}$ length. PSF can provide detailed deposition of radionuclide above the ground via its slow movements. A plastic scintillator was settled in the core of an optical fiber, SCSF-3HF (Kuraray Co. Ltd., Tokyo, Japan). The diameter and length of the fiber were $1 \mathrm{~mm}$ and $20 \mathrm{~m}$, respectively. We gathered 19 PSFs into one vinyl tube with photomultiplier tubes at both ends of the optical fiber. The scintillation light was transmitted to both ends of the fiber after entering the radiation (beta and gamma-ray) from radionuclides into the PSF. The light was converted into an electrical signal using the photomultiplier tube, which records the time lag at both ends based on the time-of-flight method. The time lag is converted into a voltage value using a time-to-amplitude converter. The voltage value is shown as a spectrum with a computer through a multi-channel analyzer. In this manner, we could determine the position of radionuclides using the PSF [6].

\subsection{Calculation conditions}

\subsubsection{Conversion of count rate to air dose rate}

Conversion of the gamma-ray count rate obtained via ARM and GRM was needed to obtain the air dose rate at $10 \mathrm{~cm}$ agl. for comparing the results of the handheld survey meter. The attenuation factor (AF) $\left[\mathrm{m}^{-1}\right]$ was used to calibrate the ARM results at different altitudes $(10-50 \mathrm{~m})$ because the attenuation of gamma rays increased with an increase in the flight altitude. The conversion factor (CD) $\left[\mu \mathrm{Sv} \mathrm{h}{ }^{-1} \mathrm{cps}^{-1}\right]$, which converts the count rate obtained via ARM into the air dose rate, was calculated based on results obtained from the calibration point at the site. In ARM using the unmanned helicopter, we defined the measured data at different altitudes using Equation (1), which is as follows:

$$
D^{\prime}=C D \times\left(C_{\text {all }}-B G_{\text {self }}\right) \times \exp \left(-A F \times\left(H_{\text {std }}-H_{m}\right)\right)
$$

where $D^{\prime}$ is the converted air dose rate measured by each tool, $C_{\text {all }}$ is the total count rate, $B G_{\text {self }}$ is the count rate derived from self-contamination of the detector and the helicopter, $H_{s t d}$ is the standard altitude above the ground level, and $H_{m}$ is each measurement's altitude.

In ARM using the drone, we defined the measured data at different altitudes using Equation (2), which is as follows:

$$
D^{\prime}=C D \times\left(C_{\text {all }}-B G_{\text {self }}\right)
$$

Altitude correction was not necessary in ARM using the drone because the altitude was constant ( $5 \mathrm{~m}$ agl.) based on altitude data by GPS.

In GRM using the truck and car, we defined the measured data using Equation (3), which is as follows:

$$
D^{\prime}=C D \times C_{\text {all }}
$$

In this case, few influences from gamma rays derived from self-contamination of the detector and tools were detected. It was not necessary to account for these influences.

\subsubsection{Evaluation method using a statistical approach}

NMSE was calculated to quantify the difference between the measured value and the standard value. The NMSE value decreased with an increase in the accuracy of the measured data.

$$
N M S E=\frac{\sum_{i=1}^{C}\left(D_{i}^{\prime}-D_{i}\right)^{2}}{\sum_{i=1}^{C} D_{i}^{2}}
$$

where $D$ is the air dose rate measured using a handheld survey meter, $C$ is the total amount of data.

\section{Results and discussion}

For comparing the air dose rate data obtained via different methods, scatter diagrams were created that depicted air dose rate by ARM (unmanned helicopter) and GRM (car) with air dose rate measured using a handheld survey meter in Figures 3 (a) and (b), respectively. In the ARM results, converted air dose rate showed a clear correlation with the results of the handheld survey meter. Converted air dose rate obtained via GRM was found to have a strong correlation with results of the handheld survey meter. It is necessary to quantify the difference of results using each tool for characterization of each measurement technique.

We focus on the average and standard deviation of air dose rate to evaluate the homogeneity of radionuclide distribution in the selected area. These values are based on the measurement results of the handheld survey meter are shown in Table 2. Overall, air dose rate of study area was uniform. For further details, Area A had a relatively high air dose rate and heterogeneous distribution because of inversion tillage, one of the decontamination strategies implemented using a plow around Area A on September, 2012. In addition, air dose rate of the forest area is relatively high (average value:

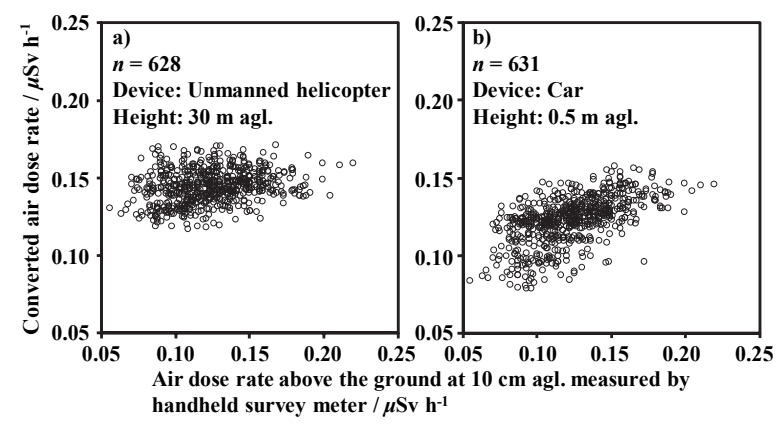

Figure 3. Relationship between the converted air dose rate and the air dose rate measured using a handheld survey meter. Each converted air dose rate was based on the following result: a) ARM using an unmanned helicopter at $30 \mathrm{~m}$ agl. and b) GRM using a car at $0.5 \mathrm{~m}$ agl. 
Table 2. Average air dose rate measured by a handheld survey meter.

\begin{tabular}{ccccc}
\hline All area & Area A & Area B & Area C & Area D \\
\hline $0.123(0.0149) ※$ & $0.136(0.0125)$ & $0.104(0.00629)$ & $0.122(0.00652)$ & $0.121(0.00906)$ \\
\hline
\end{tabular}

$※($ ): Standard deviation of the air dose rate

Table 3. NMSE of ARM and GRM in the selected area.

\begin{tabular}{|c|c|c|c|c|c|c|c|}
\hline \multirow{2}{*}{ Device } & \multirow{2}{*}{ Detector } & \multirow{2}{*}{ Height } & \multicolumn{5}{|c|}{ Measurement area } \\
\hline & & & All area & Area A & Area B & AreaC & Area D \\
\hline \multirow{4}{*}{$\begin{array}{l}\text { Unmanned } \\
\text { helicopter }\end{array}$} & & 10 & & 0.0335 & & & \\
\hline & $\mathrm{LaBr}_{3}(\mathrm{Ce})$ & 20 & 0.0711 & 0.0420 & 0.1211 & 0.0416 & 0.1013 \\
\hline & & 30 & 0.0734 & 0.0426 & 0.1295 & 0.0448 & 0.1035 \\
\hline & $\mathrm{CeBr} 3$ & 10 & 0.0446 & 0.0385 & 0.0438 & 0.0213 & 0.0554 \\
\hline Drone & $\mathrm{Gd}_{3} \mathrm{Al}_{2} \mathrm{Ga}_{3} \mathrm{O}_{12}(\mathrm{Ce})$ & 5 & 0.0460 & 0.0307 & 0.0887 & 0.0515 & \\
\hline Truck & Plastic scintillator & 0.05 & 0.0374 & 0.0350 & 0.0697 & 0.0295 & 0.0426 \\
\hline Car & $\mathrm{NaI}(\mathrm{Tl})$ & 0.5 & 0.0307 & 0.0310 & 0.0359 & 0.0217 & 0.0295 \\
\hline
\end{tabular}

\section{$\left.0.2 \mu \mathrm{Sv} \mathrm{h}^{-1}\right)$.}

For the evaluation of the confidence level for each measurement tool, NMSE values were calculated and compared. Calculated NMSE values are shown in Table 3. Measurement results of the handheld survey meter were standardized, as shown in Figure 1. Considering the NMSE values calculated using data from all sites, it was predictably found that the NMSE of GRM was smaller than that of ARM.

In ARM, the NMSE value was decreased with a decrease in the altitude of the helicopter mounting $\mathrm{LaBr}_{3}(\mathrm{Ce})$. These results indicated that the lower height of the detector became, the more its detection range of radiation was limited. Moreover, it is possible to precisely evaluate the air dose rate using the tools. On the contrary, NMSE value of the unmanned helicopter at $10 \mathrm{~m}$ agl. was almost equivalent to that of the truck and the car. This result suggested that reliability of ARM may not necessarily become worse than that of GRM.

Regarding the NMSE values in each area, the values of ARM in Areas B and D was bigger than those in Areas A and C. The NMSE value of ARM is expected to be bigger than that of GRM in instances of non-uniformity of air dose rate distribution. However, homogeneity of air dose rate in Areas B and D was not greater than that in Areas A and C, as shown in Table 2.

\section{Conclusion}

We performed ARM and GRM using various tools in the same extended farm in Fukushima prefecture. NMSE was calculated based on results obtained using a handheld survey meter to quantify the reliability of each measurement technique. It was proved that GRM tools were effective for precise investigation of air dose rate above the ground in relatively low-dose areas compared to ARM tools. NMSE of ARM depended on the altitude of tools. Few studies have discussed the payload of vehicles, the scale and conditions of the targeted environment, and the time needed to monitor the air dose rate in the area. Our results provide a great approach for effective selection of tools to measure the air dose rate in various environments. Moreover, future work is needed to quantify the difference of NMSE under different ranges of air dose rates and measurement altitudes.

\section{Acknowledgements}

This research was supported by grants from the NARO Bio-oriented Technology Research Advancement Institution (the special scheme project on regional developing strategy).

\section{References}

[1] K. Saito, I. Tanihata, M. Fujiwara, T. Saito, S. Shimoura, T. Otsuka, Y. Onda, M. Hoshi, Y. Ikeuchi, F. Takahashi, N. Kinouchi, J. Saegura, A. Seki, H. Takemiya and T. Shibata, Detailed deposition density map constructed by large scale soil sampling for gamma-ray emitting radioactive nuclides from the Fukushima Dai-ichi Nuclear Power Plant accident, J. Environ. Radioact. 139 (2015), pp. 308-319.

[2] Y. Sanada, T. Sugita, Y. Nishizawa, A. Kondo and T. Torii, The aerial radiation monitoring in Japan after the Fukushima Daiichi nuclear power plant accident, Prog. Nucl. Sci. Technol. 4 (2014), pp. 76-80.

[3] Y. Sanada, A. Ishizaki, Y. Nishizawa and Y. Urabe, Airborne radiation monitoring using a manned helicopter, BUNSEKI KAGAKU, 66 (2017), pp 149-162 [in Japanese]. 
[4] Y. Sanada and T. Torii, Aerial radiation monitoring around the Fukushima Daiichi nuclear power plant using an unmanned helicopter, J. Environ. Radioact. 139 (2015), pp. 294-299.

[5] Y. Sanada, T. Orita and T. Torii, Temporal variation of dose rate distribution around the Fukushima Daiichi nuclear power station using unmanned helicopter, Appl. Rad. Isot. 118 (2016), pp. 308-316.

[6] H. Gamo, M. Kondo, T. Hashimoto, R. Tayama and T. Tsukiyama, Development of a PSF-detector for contaminated areas, Prog. Nucl. Sci. Technol. 4 (2014), pp 695-698.

[7] Y. Sanada, Y. Urabe, T. Orita, Y. Takamura and T. Torii, In-situ measurement of radiation distribution in bottom sediments of irrigation ponds using plastic scintillation fiber, Proc. Int. Conf. on Nucl. Eng. (ICONE23), May 17-21, 2015, Chiba, Japan, (2015). [CD-ROM]

[8] M. Tanigaki, R. Okumura, K. Takamiya, N. Sato, H. Yoshino and H. Yamana, Development of a car-borne $\gamma$ ray survey system, KURAMA, Nucl. Instrum. Meth. Phys. Res. A. 726 (2013), pp. 162-168.

[9] K. Ochi, M. Sasaki, M. Ishida, S. Hamamoto, T. Nishimura and Y. Sanada, Estimation of the vertical distribution of radiocesium in soil on the basis of the characteristics of gamma-ray spectra obtained via aerial radiation monitoring using an unmanned helicopter, Int. J. Env. Res. Pub. He. 14 (2017), pp. 926-939. 